\title{
Aerothermal Testing for Project Orion Crew Exploration Vehicle
}

\author{
Scott A. Berry ${ }^{1}$ and Thomas J. Horvath ${ }^{*}$ \\ NASA Langley Research Center, Hampton, VA, 23681 \\ and \\ Randolph P. Lillard, ${ }^{2}$ Benjamin S. Kirk, ${ }^{\dagger}$ and Amy M. Cassady ${ }^{\dagger}$ \\ NASA Lyndon B. Johnson Space Center, Houston, TX, 77058
}

\begin{abstract}
The Project Orion Crew Exploration Vehicle aerothermodynamic experimentation strategy, as it relates to flight database development, is reviewed. Experimental data has been obtained to both validate the computational predictions utilized as part of the database and support the development of engineering models for issues not adequately addressed with computations. An outline is provided of the working groups formed to address the key deficiencies in data and knowledge for blunt reentry vehicles. The facilities utilized to address these deficiencies are reviewed, along with some of the important results obtained thus far. For smooth wall comparisons of computational convective heating predictions against experimental data from several facilities, confidence was gained with the use of algebraic turbulence model solutions as part of the database. For cavities and protuberances, experimental data is being used for screening various designs, plus providing support to the development of engineering models. With the reaction-control system testing, experimental data were acquired on the surface in combination with off-body flow visualization of the jet plumes and interactions. These results are being compared against predictions for improved understanding of aftbody thermal environments and uncertainties.
\end{abstract}

\section{Introduction}

$\mathrm{T}$ HE Project Orion Crew Exploration Vehicle (CEV) concept was defined by NASA's Exploration Systems Architecture Study ${ }^{i}$ (ESAS) conducted in 2005, which was chartered to define requirements for crew and cargo launch systems to support lunar and Mars exploration programs as well as access to the International Space Station (ISS). The Orion CEV is intended to provide transportation first to the ISS, then to the moon, and finally to Mars. The Crew Module (CM) of the CEV (shown in Fig. 1) has a configuration that is externally similar to the Apollo Command Module - a spherical-segment heat shield joined by a small toroidal section to a truncated-cone shaped crew compartment. The Orion CM, however, will be considerably larger than Apollo with a maximum heat shield

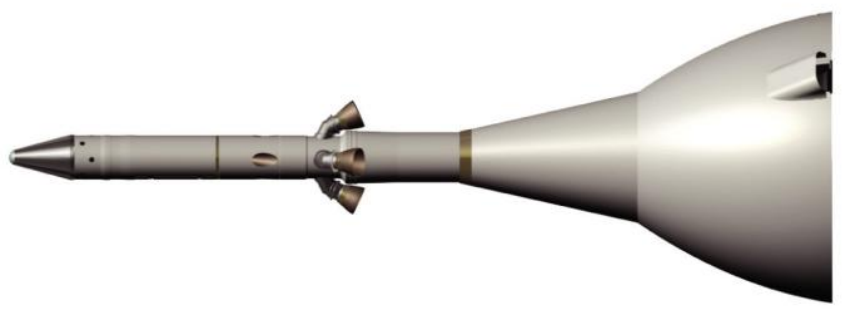

Launch Abort System (LAS)

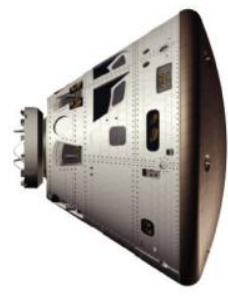

Crew Module (CM)

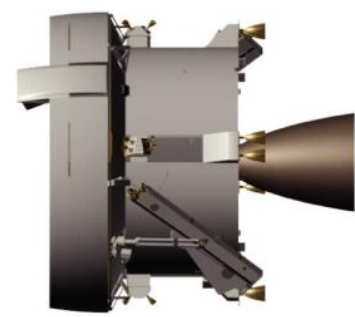

Service Module (SM)

Figure 1. Present conceptualization of Orion Crew Exploration Vehicle components

\footnotetext{
${ }^{1}$ Aerospace Engineer, Aerothermodynamics Branch, M/S 408A, Associate Fellow AIAA.

${ }^{2}$ Aerospace Engineer, Applied Aeroscinces and CFD Branch, M/C EG3, Member AIAA.
} 
diameter of $\sim 16.5 \mathrm{ft}$ (current configuration) vs. $12.8 \mathrm{ft}$ for Apollo. This larger size will allow transport of up to six crewmembers on ISS missions or up to 4 crewmembers on lunar missions. The first missions for Orion are currently scheduled for 2015 to ISS and 2020 to the moon.

For the Orion heat shield, required to protect the spacecraft and astronauts from heating during re-entry into earth's atmosphere, a glass-phenolic ablative honeycomb design based on Avcoat (similar to what was used during Apollo) has been identified as the primary candidate. The other candidate, Phenolic Impregnated Carbon Ablator (PICA), as shown in Fig. 2 , is being carried as a back-up concept. The down select process between these two options was recently completed. A major difference between these two concepts is that the Avcoat design will result in a

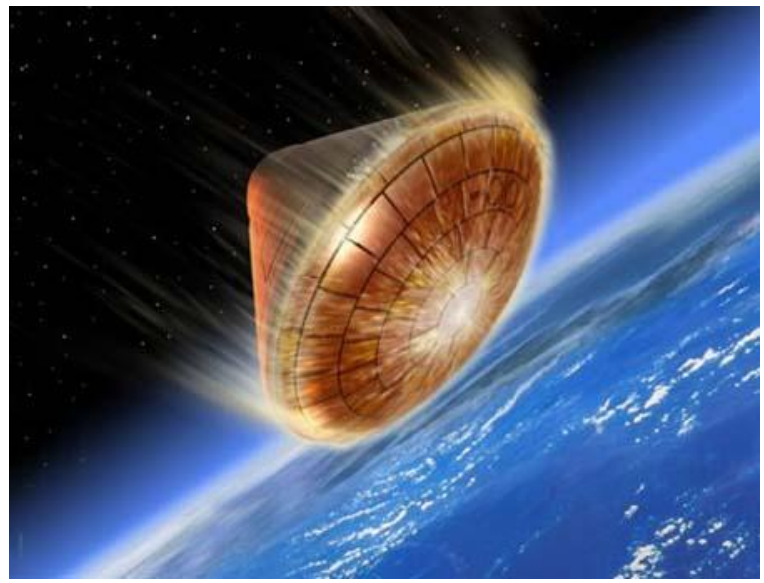

Figure 2. Artistic rendering of Orion reentry with a PICA-type heat shield monolithic heat shield, while the PICA design will have a heat shield built up of many tiles, as shown in Fig. 2, which introduces the issue of tile-to-tile steps and gaps. It should be noted that the thermal protection system (TPS) design community has adopted a conservative approach whereby the heat shield will be sized based on fully turbulent flow from entry interface along the entire trajectory. The aerothermal environments and database used to influence the final design of the TPS and structural interfaces will be determined from a combination of computational and experimental results taking into account both convective and radiative heat transfer. On the experimental side, a testing program has been developed that investigates both types of heat transfer and utilizes most of the major national facilities. The focus of the present paper is to provide insight into the Orion CM aerothermodynamic experimental program and is intended as an update to Ref. ii.

\section{Database Development}

The current philosophy for development of the aerothermodynamic database for CEV is to rely primarily on computational tools and methods. Ground-based experimental results provide validation data for targeted flow physics, shown in Fig. 3, that carry the largest uncertainties and provide data for the creation of engineering models where the CFD is known to be inadequate. The smooth body database is being developed using the engineering method CBAERO (see Ref. iii) to bridge between high fidelity computational solutions for a limited number of database anchoring points ( 400 CFD solutions over a range of Mach numbers, dynamic pressures, and angles of attack) to provide the smooth body environments along the entire trajectory for a limited number of body points ( 18,000 surface nodes). The CBAERO database provides convective heating, radiative heating, pressure, skin friction, and boundary layer properties. The CFD codes used to populate the database have been compared and

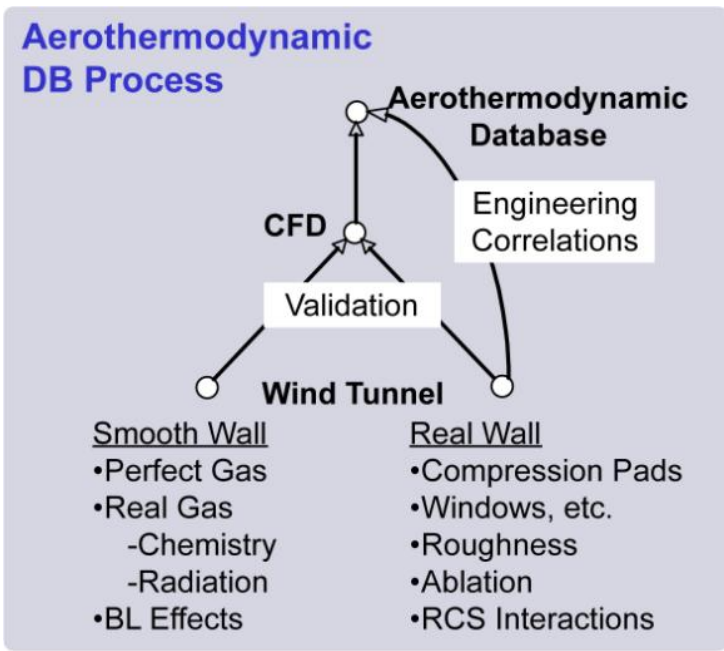

Figure 3. Wind tunnel support to the development of the aerothermodynamic database

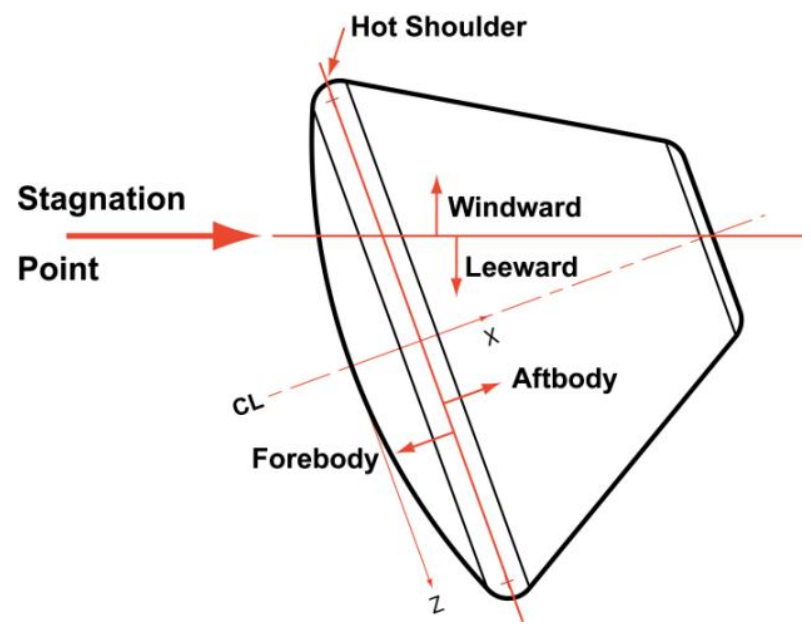

Figure 4. Framework definition for a CEV entry 
validated against the appropriate ground based data and analytical models. Also, the CFD methods have been compared against historical flight data, where appropriate, as part of the effort to develop "best practices" and uncertainty assessments. ${ }^{\mathrm{iv}, \mathrm{v}}$ To provide environments for deviations to the smooth body (the real wall issues listed in Fig. 3), engineering correlations are created using any available data from wind tunnel and flight, as well as CFD simulations. These correlations provide bump factors that are applied to the smooth body database. A framework is provided in Fig. 4 for defining the different regions of the CM, as referred to in the present paper, with the heat shield typically referred to as the forebody and the leeward aftbody being the highly separated flow section furthest away from the stagnation region.

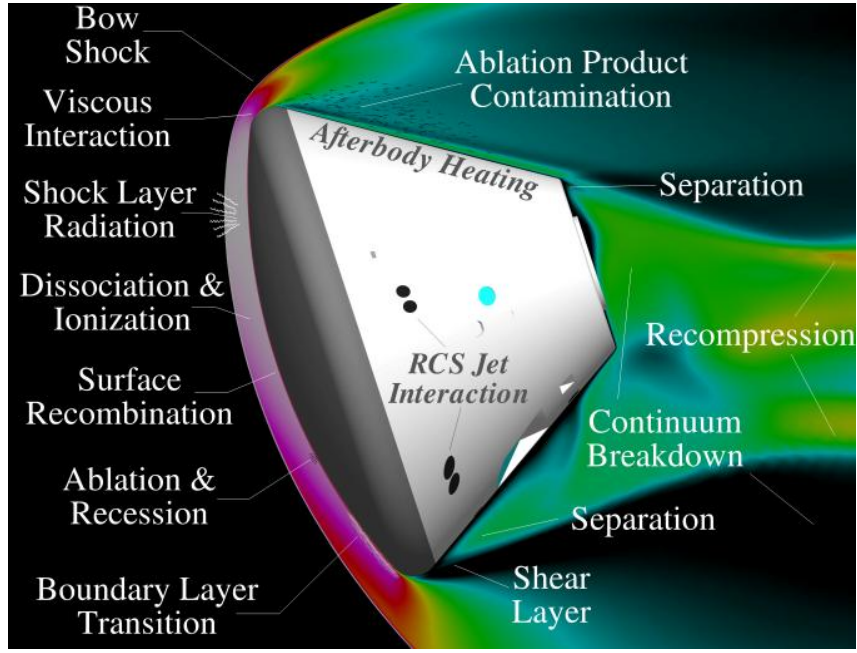

Figure 5. Flow phenomena relevant to a CEV entry

Figure 5 provides a sketch showing some of the key phenomenological issues associated with CM reentry. Many of these issues are interrelated and highly coupled. The present paper will provide insight into experimental activities that have been aligned with the disciplines outlined in Fig. 3, which should provide insight into most of the issues identified in Fig. 5. Both smooth-wall real gas (chemistry and radiation) and micro-aeroheating (such as local augmentations due to compression pads, windows, or jet interactions) effects are being investigated in ground-based facilities. These experimental data will allow "best practices" assessment of state-of-the-art computational methods and the resulting uncertainties. Also, these data will provide a technical basis for the development of engineering methodologies for assessing local flow phenomena within the aeroheating database.

One such engineering level correlation is the development of methodology to account for heating augmentations due to the presence of a distributed surface roughness. During the high velocities associated with lunar return, pyrolysis (charring and out gassing) of the heat shield will occur as it ablates during entry, thereby creating a surface roughness that differs significantly from the original surface. Despite the fact that fully turbulent heating rates are being used to design the TPS, experimentally derived augmentations to the smooth-wall heating calculations due to roughness will also be required. These effects have been studied in the past with indications of augmentations on the order of $30 \%$, but for significantly different configurations. For instance, Dirling ${ }^{\mathrm{vi}}$ and others ${ }^{\mathrm{vi}, \text { viii }}$ studied the effect of rough-wall heat transfer on reentry nosetips. Also, Voisinet investigated the combined effect of roughness and mass transfer. ${ }^{\text {ix }}$ A series of tests have been undertaken to investigate on the CEV configuration the effect of surface roughness and blowing on turbulent heating, of which further details will be provided in the experimental studies section. Another engineering level assessment is to account for known surface irregularities in the Orion OML that are a result of the attach hardware design for holding the CM on the service module, SM (also shown in Fig. 1). A series of densified TPS "compression pads" located near the outer diameter of the heat shield will seat the $\mathrm{CM}$ in place, transfer vehicle loads during ascent and prevent torsional rotation. A cylindrical tension tie rod will secure the $\mathrm{CM}$ in place until re-entry. The design is similar to that used for Apollo, see Fig. 6. During CM separation, the tension tie rods are to be severed just above the surface. The local heating environment produced by the tie rod protuberance was the subject of the Apollo era experimental study by Bertin $^{\mathrm{x}}$ and a more recent investigation by Liechty ${ }^{\mathrm{xi}}$ in support of Orion.

Several working groups have been set up within the CEV Aerosciences Project (CAP) to organize discussion, analysis, and reviews of pertinent data relevant to each discipline. Currently there are working groups for the following disciplines: (1) smooth body to coordinate all the smooth body computations and

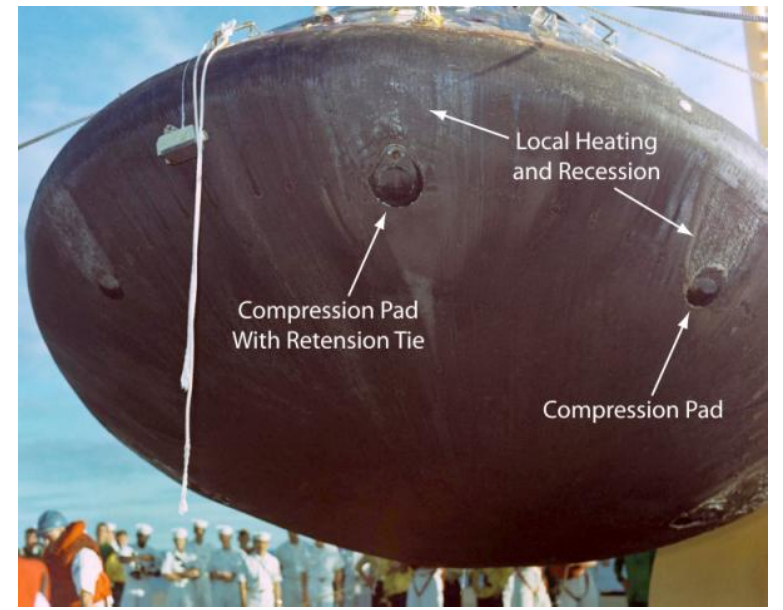

Figure 6. Post-flight photograph of Apollo 10 showing compression pads and local recession 
comparison against the smooth model data; (2) launch abort system (LAS, also shown in Fig. 1) to cover most Orion heating related issues during launch; (3) reaction control system (RCS) for determining the heating augmentations due to the complicated three-dimensional interactions of the RCS jets with the aftbody flow environment (see Fig. 7 for an example from Apollo); (4) compression pad and tension tie to handle the local heating within and around the forebody heat shield irregularities; (5) cavity heating for accounting for all the deviations to the smooth OML on the aftbody; (6) roughness and blowing for determining the turbulent augmentation factors for the post-ablation roughened heat shield and to account for ablation effects; and finally, (7) radiation to properly assess the shock layer radiation for a lunar return. These working groups have broad membership from experts within each discipline from across the country.

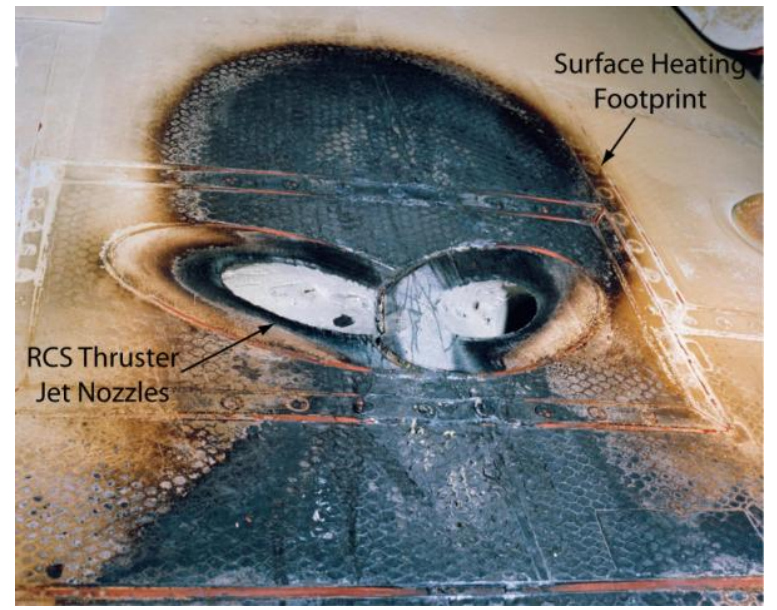

Figure 7. Post-flight photograph of Apollo 6 showing RCS nozzles and heating augmentations

Uncertainties in the output quantities from the CBAERO database have been developed based on engineering judgment that factors in the experience of historical programs, such as Apollo, Shuttle, and various planetary programs. Ground testing has also provided invaluable information for assessing the uncertainties for the analytical tools and computational methods. The uncertainties developed thus far for the database are applicable to the smooth body Design Analysis Cycle 2 (DAC2) CM geometry during reentry (from both low Earth orbit and lunar returns) and abort scenarios. For reentry, these uncertainties are relevant from entry interface to approximately Mach 1.3 where convective cooling on the Crew Module begins to become dominant. As part of a conservative heat shield design policy, an all-turbulent heating profile has been assumed, thus the uncertainties developed so far are primarily associated with turbulent convective and radiative heating. However, some results of laminar heating analysis and test data have also influenced the process with regard to the recommended uncertainties for the overall $\mathrm{CM}$ aerothermal environments. Limited test data are available for reentry of capsule-like configurations. The Apollo CM has limited flight data available for comparisons, however, the CEV geometries and trajectories differ enough from the Apollo Program that the data are used for trend comparisons only. The CEV configuration data are utilized as appropriate for the code-to-test data comparison. The present aeroheating uncertainties have been assessed as follows: for return from low Earth orbit, convective heating on the forebody and windward aftbody is estimated to be accurate to within $15 \%$ for laminar and $25 \%$ for turbulent, and for the leeward aftbody, $30 \%$ for both laminar and turbulent; for return from lunar, convective heating on the forebody and windward aftbody is estimated to be accurate to within $20 \%$ for laminar and $35 \%$ for turbulent, and for the leeward aftbody, 50\% for both laminar and turbulent, while for radiative heating is estimated to be accurate to within $56 \%$ for both laminar and turbulent.

\section{Facilities}

\section{A. LaRC Mach 6 \& 10}

Aerothermal testing has been conducted at NASA Langley Research Center (LaRC) in Hampton, Virginia on several CEV configurations in both the 20-Inch Mach 6 Air and the 31-Inch Mach 10 Air Tunnels. Both these facilities are conventional blow-down tunnels that utilize dried, heated, and filtered air as the test gas. Typical aerothermal test techniques that are utilized in these tunnels are thermocouples, thin-film, thin-skin, schlieren, oilflow, and phosphor thermography, which is used to provide quantitative global temperature and, thus, heat transfer images. Detailed descriptions of these facilities, along with their associated instrumentation and test techniques can be found in Refs. xii and xiii.

Typical operating conditions for the LaRC 20-Inch Mach 6 Air Tunnel are stagnation pressures ranging from 30 to 500 psia, stagnation temperatures from 410 to $500^{\circ} \mathrm{F}$, and free stream unit Reynolds numbers of 0.5 to $7.8 \times 10^{6} / \mathrm{ft}$. A two-dimensional, contoured nozzle is used to provide a nominal freestream Mach number of 6 . The test section is 20.5 by 20 inches. A bottom-mounted model injection system inserts models from a sheltered position to the tunnel centerline in less than 0.5 -sec. Run times of up to 15 minutes are possible with this facility, although for typical heat transfer and flow visualization tests, only a few seconds are required. Optical access to the model is viewed through a high-quality window on the top of the tunnel for phosphors and oil-flow, while high-quality windows on the side provide schlieren access. 
Typical operating conditions for the LaRC 31-Inch Mach 10 Air Tunnel are stagnation pressures ranging from 350 to 1450 psia and a stagnation temperature on the order of $1350^{\circ} \mathrm{F}$, which yields freestream unit Reynolds numbers of $0.5 \times 10^{6} / \mathrm{ft}$ to $2.2 \times 10^{6} / \mathrm{ft}$. The tunnel has a closed 31 - by 31 -in. test section with a contoured threedimensional water-cooled nozzle to provide a nominal Mach number of 10. A hydraulically operated side-mounted model injection mechanism injects the model into the flow in 0.6 seconds. The maximum run time for this facility is approximately 2 minutes; however, only 5 seconds of this time is typically required for transient heat transfer tests. Optical access to the model mechanism for both phosphors and oil-flow is through a high-quality side window.

\section{B. Cal Tech T5}

Several experiments were performed in the T5 free-piston shock tunnel at the California Institute of Technology in Pasadena, California to obtain total enthalpy levels not available from perfect-gas facilities. The T5 facility is described in detail in Ref. xiv. Briefly, T5 is a piston-driven reflected shock tunnel that generates short-duration hypervelocity flows for simulation of real-gas flight environments. High-pressure air is used to drive a heavy piston, thus rapidly heating and accelerating the driver gas in front of it to high temperatures and pressures. A reflected shock wave processes the test gas, which is then expanded through a conical nozzle to high velocities producing high enthalpy flows (ranging from $10-20 \mathrm{MJ} / \mathrm{kg}$ ) of sufficient duration to ensure brief but steady flow over the model. Typical test times are in the range of 1 to 2 milliseconds. Aerothermal test techniques typically used in this facility are traditional schlieren imagery and surface thermocouple instrumentation. The thermocouples used in T5 are of custom design and evolved from the work of Sanderson. ${ }^{\mathrm{xv}}$ The key design feature is the tapered thermocouple centerpiece, which causes the thermocouple material junction to be a very shallow depth confined to the surface of the model. This specific design feature is required to measure the surface temperature rise of the model, which is necessarily confined to a very shallow depth due to the short run times characteristic of the facility.

\section{AEDC Tunnel 9}

The Air Force's Arnold Engineering Development Center Hypervelocity Tunnel 9 located in Silver Spring, Maryland, is a hypersonic, nitrogen-gas, blow-down wind tunnel with interchangeable nozzles that allow for testing at Mach numbers of 7, 8, 10, and 14 over a large Reynolds number range. More detailed information on this facility can be found in Refs. xvi, xvii, xviii, xix. The tunnel has a 5 -ft-diameter, 12-ft-long test section that permits test of large-scale model configurations. Tunnel 9 features a pitch system that can sweep models from -10-deg to 50-deg at pitch rates up to $80 \mathrm{deg} / \mathrm{sec}$. With the tunnel's $0.2 \mathrm{sec}$ to $15 \mathrm{sec}$ run times, the dynamic pitch capability allows for a large volume of data to be captured over an entire range of pitch angles during a single run. During a run, nitrogen in the vertical gas heater is compressed and heated to a desired pressure and temperature, where the maximum conditions are $27 \mathrm{kpsi}$ and $3040^{\circ} \mathrm{F}$. The nozzle and test cell are evacuated to a pressure of less than $0.02 \mathrm{psi}$ and are isolated from the high-pressure side by a pair of metal diaphragms upstream of the throat. When the desired conditions are reached in the heater, the diaphragms are burst and the high-pressure/high-temperature nitrogen expands through the nozzle into the test cell. During the run, the driver vessels use cold gaseous nitrogen to replace the hot gas in the heater to maintain constant supply conditions. Typical aerothermal test techniques for this facility are schlieren imagery and surface heat transfer measurements using one of several techniques. The schlieren instrumentation at AEDC acquires data at a high frame rate (up to $10 \mathrm{kHz}$ ), and the frame exposure is coupled to a fast-acting laser light source that significantly reduces image "blur" which would otherwise occur at hypervelocity flow conditions. The surface heat transfer measurement techniques include standard Type-E thermocouples, Schmidt-Boelter gages, and infrared thermography.

\section{CUBRC LENS I \& XX}

Several aerothermal tests in this program were performed in and are being planned for the Calspan-University of Buffalo Research Center (CUBRC) Large Energy National Shock (LENS) I and LENS XX facilities. These facilities share a common compressor system and data recording system. LENS I was constructed with the capability to fully duplicate flight conditions at Mach numbers ranging from 7 to 16 and to conduct testing with fullscale versions of missile interceptors and scramjet engines. The major components of the LENS I facility include a 25.5-foot long by 11-inch diameter electrically heated driver tube, a double diaphragm assembly, a 60 -foot by 8-inch diameter driven tube, a fast acting center body valve assembly, multiple nozzles to achieve desired test conditions from Mach 7 to 24, and a test section capable of accommodating models up to 3 feet in diameter and 12 feet long. The high-pressure driver section of LENS I has the capacity to operate at 30,000 psi using heated driver gases of hydrogen, helium, nitrogen or any combination of the three. The driver gases can be heated up to $750^{\circ} \mathrm{F}$ and the amount of each gas varied to achieve tailored interface operations for maximum test times. The driven tubes of either facility can use air, nitrogen, carbon dioxide, helium, hydrogen or any other gases or combinations of gases 
for model testing. LENS XX is a new capability, designed to duplicate high enthalpy flows within an expansion tunnel at Mach numbers ranging from 8 to 25. The major components of LENS XX include a 15-foot by 2 -ft diameter driver tube, a double diaphragm assembly, a 39-foot long driven tube, an 88.5-foot long expansion tube, multiple nozzles, and a test section capable of accommodating models up to 2 feet in diameter and 10 feet long. LENS XX has the capacity to utilize hydrogen, helium, nitrogen, air, carbon dioxide, methane or any combination of these as the test gas. Surface heat transfer measurement techniques typically include thin-film, calorimeter, and thermocouples, temperature sensitive paints, and infrared thermography. Further discussions of LENS facility capabilities can be found in Ref. xx.

\section{E. ARC EAST}

The NASA Ames Research Center Electric Arc Shock Tube (EAST) facility at Moffett Field, California has the capability to generate shock-heated air with representative lunar-return velocities and pressures. For lunar returns, shock-layer radiation will constitute a significant portion of the total heat flux to the vehicle surface in the peakheating region of the entry trajectory. Phenomenological models of non-equilibrium radiation transport will be incorporated into high-fidelity CFD predictions of the aerothermal environments for Orion. These models are validated with shock-heated gas radiation measurements obtained at flight-relevant conditions. The measurements are made with sufficient spatial, temporal, and spectral resolution to characterize state-specific kinetic processes behind a shock wave that arise during reentry. Typical test times for EAST are on the order of several microseconds, which is often sufficient to capture the peak of the nonequilibrium shock radiation and the decay to equilibrium conditions. The facility was built in the late 1960s to support research in aerothermochemistry of hypervelocity flight through Earth and planetary atmospheres. The use of an electric arc discharge as the driver mechanism permits generation of shock speeds up to $50 \mathrm{~km} / \mathrm{s}$ in $\mathrm{H} 2 / \mathrm{He}$ atmospheres. These high shock speeds greatly exceed those achieved with heated light gas, combustion, or free piston drivers. More detailed descriptions of the facility can be found in Refs. xxi, xxii, and xxiii.

\section{Experimental Studies}

\section{A. Perfect Gas}

Several tests have been conducted to provide smooth model experimental data from conventional hypersonic facilities at both laminar and turbulent conditions, see Table 1 . These studies were intended to provide high quality datasets for comparison to computational predictions in support of the smooth body working group and development of the various versions of the aerothermodynamic database. The first two studies $(31-\mathrm{CH}$ and $32-\mathrm{CH})$ included "best practices" principles to investigate model blockage and sting effects with the global phosphor thermography test technique to both determine the largest model that could be tested in the LaRC Mach 6 and 10 facilities as well as to understand the effect of sting placement. Results from the Mach 6 tunnel provided CAP the first comparisons of predictions to turbulent data, although with boundary layer trips. These results have been recently reported in Ref. xxiv. The next test, 36-CH, utilized a highly instrumented thermocouple $3.5 \%$-scale model to acquire data from AEDC Tunnel 9 over as wide a range of Reynolds numbers as possible. ${ }^{x x v}$ This test was able to measure turbulent heating data without the use of trips for comparison against turbulent calculations. Recently, some TSP results on this model were published, see Ref. xxvi. This same model was later tested in the LaRC Mach 6 tunnel with 56-CH, see Ref. xxvii, in order to compare measurements made from different models and techniques. A comparison of these results is provided in Ref. xxviii. Figure 8 provides a photograph of the model used for these two studies as installed within the LaRC Mach 6 tunnel. Finally, a test was recently completed in the CUBRC LENS I facility $(67-\mathrm{CH})$ to obtain high fidelity data using a combination of thermocouples over a majority of the model and thin-film gages around the hot shoulder. The results of this study were recently published in Ref. xxix. One of the impacts, thus far, from this round of testing was to help resolve issues with the selection of a turbulence model for use by the

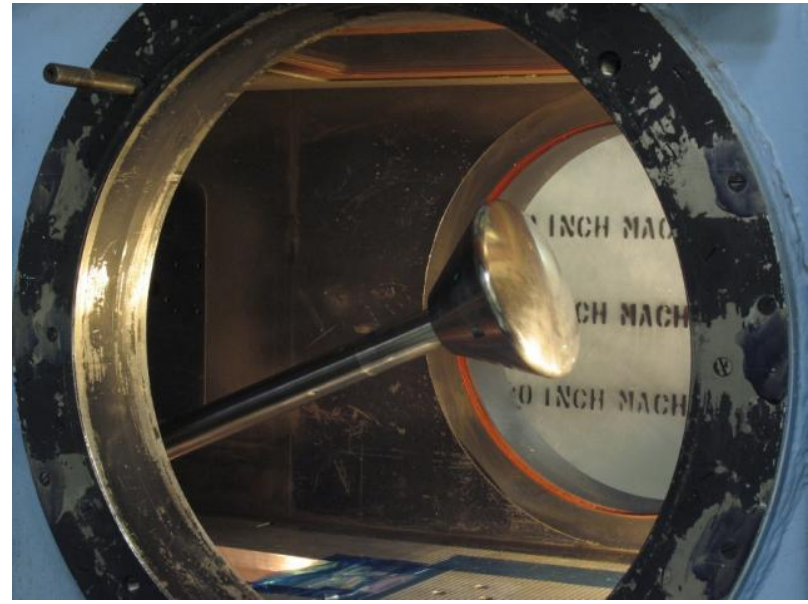

Figure 8. CEV model shown injected into the LaRC 20-In Mach 6 Air Tunnel 
program. Initially there was some interest in using Menter's shear stress transport (SST) ${ }^{\mathrm{xxx}}$ two-equation model, but the early comparisons against the experimental data showed that the simpler algebraic models, like Cebeci-Smith ${ }^{\mathrm{xxx}}$ or Baldwin-Lomax ${ }^{\text {xxii }}$, provided the best results for attached flows. At present the smooth body computational database is being built with the use of an algebraic turbulence model.

Table 1: Perfect gas studies in support of CAP

\begin{tabular}{|c|c|c|c|c|c|}
\hline $\begin{array}{c}\text { Test } \\
\text { Number }\end{array}$ & \multicolumn{2}{|c|}{ Facility } & $\begin{array}{c}\text { Principal } \\
\text { Investigator }\end{array}$ & Conducted & Emphasis of the test \\
\hline 31-CH & LaRC & M6 & Berger & Jun-06 & Tripped turbulent \\
\hline 32-CH & LaRC & M10 & Berger & Jun-06 & Aftbody heating \\
\hline 36-CH & AEDC & T9 & Hollis & Oct-06 & High Re \\
\hline 56-CH & LaRC & M6 & Hollis & Feb-07 & Phosphor vs TC, BLT \\
\hline $67-C H$ & CUBRC & LENS & Cassady & Feb-08 & Hot shoulder \\
\hline
\end{tabular}

As an example of the initial comparisons between smooth model data and computations, tests $31-\mathrm{CH}$ and $32-\mathrm{CH}$ provided experimental measurements made from both the LaRC Mach 6 and 10 facilities on several scaled ceramic heat transfer CEV models and these results are documented in one test report, Ref. xxxiii. The experimental data highlighted in the test report were used to validate numerical tools that will support the flight aerothermodynamic database development. Global heat transfer images and heat transfer distributions were obtained with the phosphor thermography technique. The heat transfer data were used to infer the boundary layer state on the forebody and the aeroheating levels on the aftbody. For the aftbody measurements, the potential for support hardware interference and the ability to provide reliable low heating measurements were assessed. The primary objective of test $31-\mathrm{CH}$ in the LaRC Mach 6 tunnel was to measure benchmark turbulent heating on the CEV heat shield. To support CFD turbulence modeling best practices and to assess numerical uncertainties, natural transition to turbulent flow was desired over turbulent flow forced from surface roughness. Test parametrics included a range of model diameters to increase length Reynolds numbers and improve the likelihood of achieving fully developed natural turbulent flow on the heat shield. A boundary layer trip strategy was developed in the event that fully developed turbulent heating could not be achieved naturally. Limited measurements on the CEV aftbody were made to assess potential model support system interference on surface heating and to determine the response of the phosphor measurement technique in regions of low surface temperature. The primary objective of test 32- $\mathrm{CH}$ in the LaRC Mach 10 tunnel was to characterize the phosphor temperature response on the aftbody in a facility with a higher temperature driver potential (and potentially higher signal-to-noise ratio and correspondingly lower measurement uncertainties than the Mach 6 facility). Measurements similar to those obtained in the Mach 6 tunnel were obtained to assess support system interference as well as the viability of testing the aftbody surfaces in either facility. Heating levels in the higher temperature facility were desired for code validation on the aftbody. Test parametrics include freestream unit Reynolds numbers of $2.1 \times 10^{6} / \mathrm{ft}$ to $7.3 \times 10^{6} / \mathrm{ft}$ and $1.0 \times 10^{6} / \mathrm{ft}$ to $1.9 \times 10^{6} / \mathrm{ft}$ in Mach 6 and Mach 10 air, respectively at a fixed angle-of-attack of $152 \mathrm{deg}$. While naturally turbulent levels were not obtained on the forebody, the use of boundary layer trips generated turbulent data at unit Reynolds numbers of $5.6 \times 10^{6} / \mathrm{ft}$ and $7.3 \times 10^{6} / \mathrm{ft}$. Figure 9 provides a comparison of the measured centerline heating at Mach 6 and $\mathrm{Re}=5.6 \times 10^{6} / \mathrm{ft}$ with and without trips to laminar and Cebeci-Smith turbulent predictions. Aftbody testing provided reliable heating data without significant model support hardware influence.

Another important example to highlight is the comparison between experimental results and predictions for test $36-\mathrm{CH}$. This study was conducted at AEDC Tunnel 9 with both the Mach 8 and 10 nozzles. Heating data were inferred from a 3.5\%-scale highly instrumented thermocouple model. Test parametrics include freestream unit Reynolds numbers of $8 \times 10^{6} / \mathrm{ft}$ to $48 \times 10^{6} / \mathrm{ft}$ and $1 \times 10^{6} / \mathrm{ft}$ to $20 \times 10^{6} / \mathrm{ft}$ with Mach 8 and Mach 10 nozzles, respectively, over a range of angles of attack of 146 to 180 deg. With nitrogen as the test gas at low enthalpy levels, perfect gas conditions were obtained. The range of Reynolds numbers

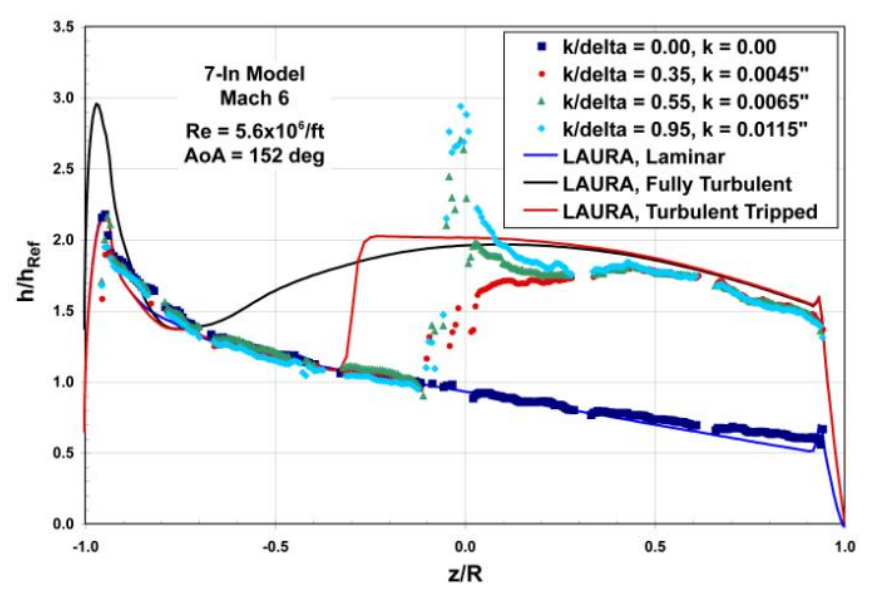

Figure 9. Comparison of measured heating from 31-CH to predictions for $\mathrm{AoA}=152-\mathrm{deg}$. 


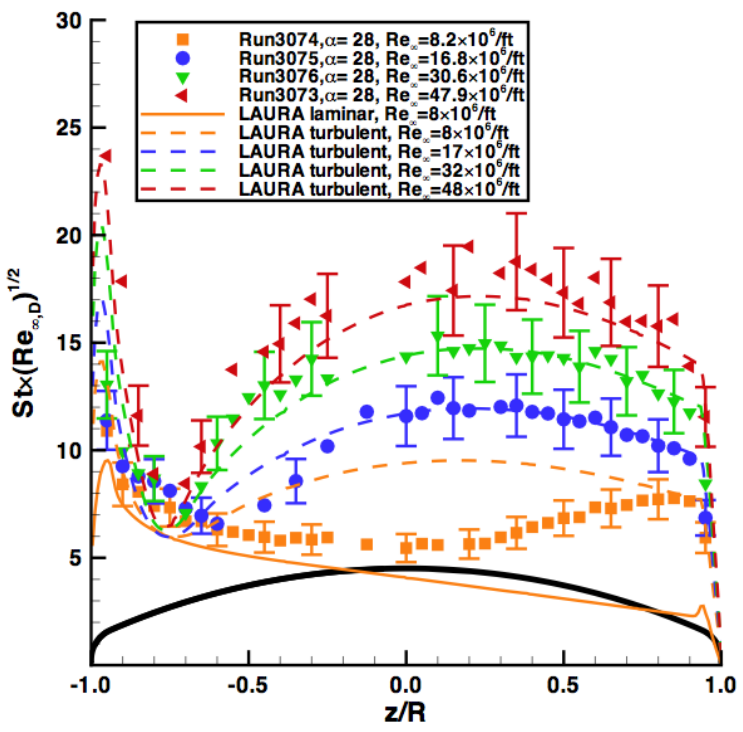

Figure 10. Comparison of measured heating from 36- $\mathrm{CH}$ to predictions for $\mathrm{AoA}=152-\mathrm{deg}$.

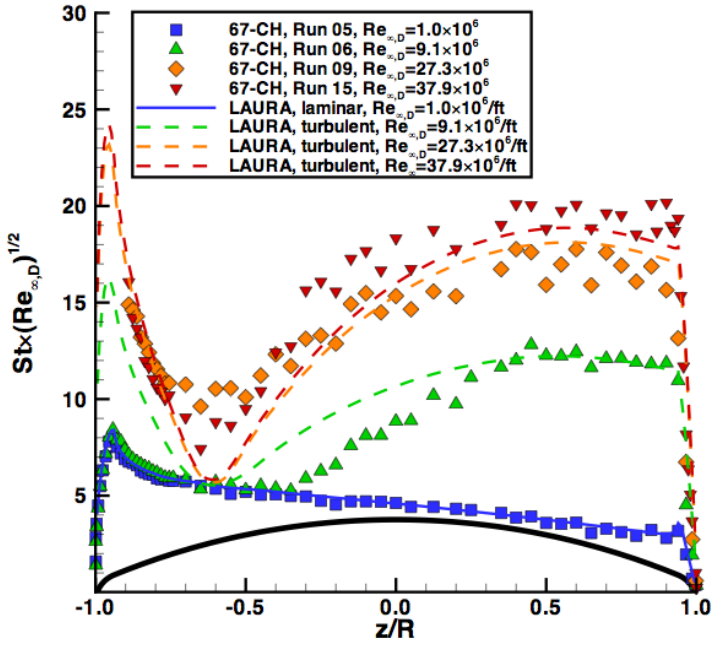

Figure 11. Comparison of measured heating from 67$\mathrm{CH}$ to predictions for $\mathrm{AoA}=160-\mathrm{deg}$.

resulted in laminar, transitional, and turbulent data on a smooth model without the need for boundary layer trips. Comparison of both the laminar and turbulent measured heating data to predictions was generally better than the $\pm 12 \%$ experimental uncertainty estimate, as shown in Fig. 10, a typical example from that test. The turbulent calculations shown utilized the Cebeci-Smith turbulence model, which provides confidence with the use of these simpler algebraic methods for attached forebody flows. ${ }^{\text {xxiii }}$ Similar results were obtained in the comparisons of the experimental results for 67-CH against the same computational method, as shown in Fig. 11.

\section{B. Real Gas}

Several tests were intended to provide smooth model experimental data from high-enthalpy hypersonic facilities (see Table 2). Thus far two entries $(35-\mathrm{CH}$ and $40-\mathrm{CH})$ have been conducted that have provided results at freestream enthalpies ranging from $10-20 \mathrm{MJ} / \mathrm{kg}$ at stagnation pressures up to $50 \mathrm{MPa}$. Unfortunately, run-to-run repeatability from these tests has not been of sufficient quality to allow real gas effects to be discerned from the experimental scatter, that typically varies on the order of $10-15 \%$, in comparison to computational models. There have been some limited low-to-moderate enthalpy runs conducted as part of other test series, which have had much better comparisons to computations. Consequently, a new test $(91-\mathrm{CH})$ is presently being developed to acquire data from a different facility for comparison. This test series will employ the LENS-XX shock-expansion facility. The relevant characteristic of the shock-expansion configuration is that the high-enthalpy test gas is never stagnated until striking the model. The tunnel freestream conditions are therefore much more relevant to typical high-enthalpy flight conditions. Until these new data are acquired and analyzed, however, flight data ${ }^{\text {iv }}$ will remain the primary source of high-enthalpy heat transfer measurements used to quantify the uncertainty in physical models.

Table 2: Real gas studies in support of CAP

\begin{tabular}{|c|c|c|c|c|c|}
\hline $\begin{array}{c}\text { Test } \\
\text { Number }\end{array}$ & \multicolumn{2}{|c|}{ Facility } & $\begin{array}{c}\text { Principal } \\
\text { Investigator }\end{array}$ & Conducted & Emphasis of the test \\
\hline 35-CH & CalTech & T5 & Olejniczak & Fall-06 & Initial study \\
\hline $40-\mathrm{CH}$ & CalTech & T5 & Kirk & Apr-08 & Repeat \& moderate enthalpy \\
\hline 91-CH & CUBRC & LENS & Kirk & Q2-FY10 & Comparison to T5 \\
\hline
\end{tabular}

\section{Radiative Heating}

For the radiative heating topic, a series of tests have been planned (see Table 3) to investigate Orion lunar-return radiative peak-heating conditions. For CEV missions returning from the moon, shock layer radiation will contribute up to half the total heat flux to the vehicle during the peak-heating portion of the entry trajectory. Having accurate models to predict the radiative component of heating, and the uncertainties that go with those predictions, is crucial to the design of the TPS for lunar return missions. A test series has been initiated in the Ames EAST facility, while another is being planned for the newly constructed CUBRC LENS XX facility. Emission spectroscopy 
instrumentation, including monochromators and imaging spectrographs, enable measurements of shocked-gas radiation spectra from the vacuum-ultraviolet (VUV) to the near infrared (NIR), which will be used to modify and verify the models of non-equilibrium radiation transport to be incorporated into high-fidelity CFD predictions and thus the database. The imaging spectrographs capture the nonequilibrium post-shock excitation and relaxation dynamics of dispersed spectral features. These data are needed to develop and validate model kinetics of excited air species. Some of the early results from the EAST facillity have already been published with comparison against theoretical models and predictions. ${ }^{\text {xxiv-xxxvii }}$ These results have allowed an improved understanding of the impact of radiative heating including uncertainties on TPS design. ${ }^{\text {xxxviii-xli }}$

Table 3: Radiation studies in support of CAP

\begin{tabular}{|c|c|c|c|c|c|}
\hline $\begin{array}{c}\text { Test } \\
\text { Number }\end{array}$ & \multicolumn{2}{|c|}{ Facility } & $\begin{array}{c}\text { Principal } \\
\text { Investigator }\end{array}$ & Conducted & Emphasis of the test \\
\hline 43-CH & ARC & EAST & Grinstead & FY06-FY07 & VUV to NIR shock radiance \\
\hline 44-CH & CUBRC & LENS X & Grinstead & FY07 & Facility capability assessment \\
\hline $71-\mathrm{CH}$ & ARC & EAST & Cruden & Q3 FY09 & $\begin{array}{c}\text { VUV to NIR shock radiance; } \\
\text { electron density measurement }\end{array}$ \\
\hline 72-CH & CUBRC & LENS XX & Grinstead & $\begin{array}{c}\text { Q3, Q4 } \\
\text { FY09 }\end{array}$ & $\begin{array}{c}\text { Limited VUV, UV-NIR shock } \\
\text { radiance (second source) }\end{array}$ \\
\hline 96-CH & ARC & EAST & Cruden & FY10 & $\begin{array}{c}\text { Expanded test envelope; } \\
\text { uncertainty estimations }\end{array}$ \\
\hline 97-CH & CUBRC & LENS XX & Grinstead & FY10 & $\begin{array}{c}\text { Second source for uncertainty } \\
\text { estimations }\end{array}$ \\
\hline
\end{tabular}

\section{Protuberances and Cavities}

Several tests, see Table 4, were conducted to provide local heating for surface features on the forebody and aftbody that would be difficult to capture with state-of-the-art computations. As mentioned previously, the heat shield irregularities are in the form of compression pads and tension ties, while the aftbody has many deviations from the smooth OML, such as windows, attachment points for the LAS, RCS nozzles, etc. The compression pads are circular cavities, while the tension ties have the potential to provide protrusions that, at present, are planned to be concentric to the center of the compression pad. While every attempt is being made to perform high fidelity computations on the appropriate compression pad and tension tie configuration for flight, the experimental data is being used to more effectively screen the parametric space of cavity depths, widths, side wall angles, etc, in combination with protrusions both in and downstream of the compression pad. In addition, these tests will be used for CFD validation and to support the development of heating augmentation analytical models that supplement the smooth model aerothermodynamic database. Test 30-CH investigated within the LaRC Mach 6 tunnel the initial concepts for the compression pad design with large tension tie protrusions both within and downstream of the cylindrical pads, see Ref xlii. Tests $86-\mathrm{CH}$ and $87-\mathrm{CH}$ provided updated information for primarily straight-wall (referred to as hockey-puck) compression pads of varying depths and heights (the protrusions were to account for extreme recession of the surrounding TPS material) in the Mach 6 and 10 tunnels, respectively, both documented in Ref. xliii. More recently, the compression pad design has included sloped sidewalls, which were then tested with 64-CH in both the Mach 6 and 10 facilities. Reference xliv provides some of the results from this test. Finally, the most up-to-date compression pad design will soon be tested with highly instrumented thermocouple models in the LENS I facility. This last test is actually planned to be broken up into two phases, one focused on the forebody, with an instrumentation layout for obtaining high fidelity data mainly around the compression pads, and the second focused on the aftbody, with an instrumentation layout for obtaining heating around the windows and other cavities due to RCS jets on and off. These two phases will have two different models, with different model scales.

Table 4: Local heating studies in support of CAP

\begin{tabular}{|c|c|c|c|c|c|}
\hline $\begin{array}{c}\text { Test } \\
\text { Number }\end{array}$ & \multicolumn{2}{|c|}{ Facility } & $\begin{array}{c}\text { Principal } \\
\text { Investigator }\end{array}$ & Conducted & Emphasis of the test \\
\hline $30-\mathrm{CH}$ & LaRC & M6 & Liechty & Jul-06 & Forebody penetrations \\
\hline $86-\mathrm{CH}$ & LaRC & M6 & Hollis & Oct-07 & Hockey puck pads \\
\hline $87-\mathrm{CH}$ & LaRC & M10 & Hollis & Nov-07 & Hockey puck pads \\
\hline $64-\mathrm{CH}$ & LaRC & M6 \& 10 & Hollis & Sept-08 & Beveled side walls \\
\hline $66-\mathrm{CH}$ & CUBRC & LENS & Lillard & Q4-FY09 & High fidelity \\
\hline
\end{tabular}


As an example of compression pad experimental results, $30-\mathrm{CH}$ was the initial investigation into the effects of both protuberances and cavities on a CEV forebody. The results of this wind tunnel heat transfer test on $3.23 \%$-scale models of the CEV Cycle I geometry are provided in Ref. xlii. Conducted in the LaRC Mach 6 tunnel for the nominal reentry angle of attack of 152 degrees with a freestream unit Reynolds number range of $1.0 \times 10^{6}$ to $7.25 \times 10^{6} / \mathrm{ft}$, this investigation was to determine interference heating patterns in the vicinity of protuberances and cavities into the NASA
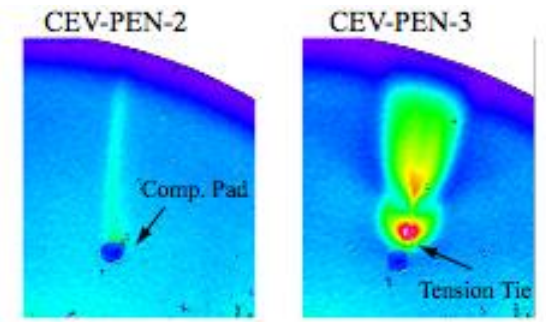

Laminar Approaching Boundary Layer
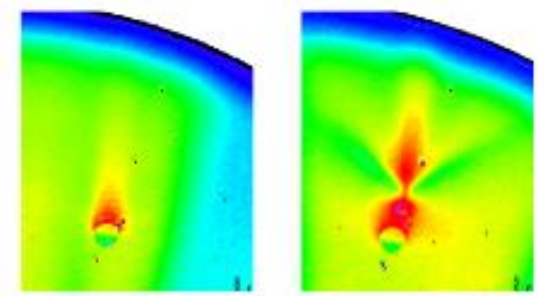

Turbulent Approaching Boundary Layer

Figure 12. Close up of local heating around leeward forebody compression pads from $30-\mathrm{CH}$.
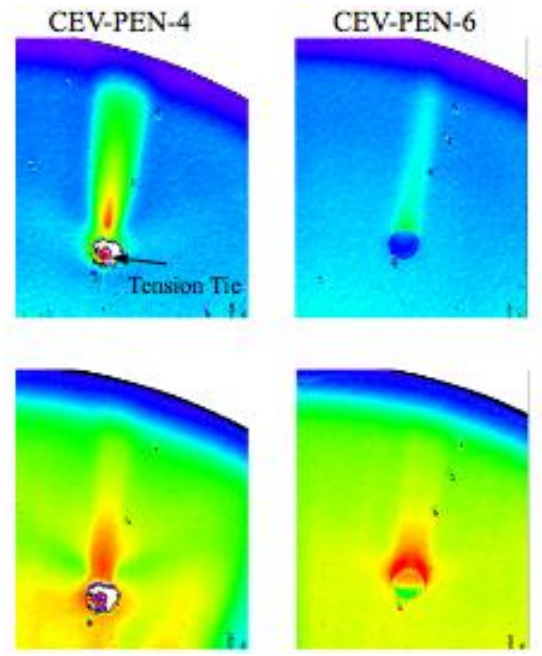
.

Cycle I CEV forebody heat

shield. These local perturbations to the baseline smooth CEV OML were intended to be a generic representation of proposed hardware designed to attach and prevent torsional rotation of CM as it sits on the SM. The attachment hardware modeled in this wind tunnel test included both tension ties and compression pads, similar to the hardware found on Apollo. The attach hardware proposed at the time of this test, called for eight equally spaced compression pad/tension tie combinations near the heat shield shoulder. This has since been changed to six equally spaced pads. Another aspect to this study was to demonstrate a laser ablation manufacturing technique to be used to accurately replicate the compression pad geometry on cast ceramic wind tunnel models and then to subsequently determine the ability of global phosphor thermography to obtain spatially resolved global surface thermal mapping patterns associated with a range of attachment hardware configurations. The data were used to provide heating reductions and/or augmentations within and in proximity to the compression pad (cavity) and tension tie (protuberance) under a laminar and turbulent approach flow. Heating augmentations were inferred from measurements made on a baseline smooth OML relative to that measured at the same locations with the cavities and/or protuberances present. These wind tunnel data were also intended to aid in the determination of optimal location of the tension tie/compression pad combination on the heat shield and to assess the potential propagation of flow disturbances (and subsequent heating) from the attachment hardware to the aftbody. These results have also been documented in Ref. xi. Figure 12 provides a representative result from this test, showing the effect of the placement of a protruding tension tie in reference to a leeward forebody compression pad under both laminar and turbulent conditions. The designations shown in the figure are as follows: PEN-2 is a compression pad with no tension tie, PEN-3 is a compression pad with the tension tie downstream, PEN-4 is a compression pad with a concentric tension tie, and PEN-6 is a slightly bigger compression pad with no tension tie. Clearly, a protruding tension tie has a significant impact on the downstream heating. See Reference xi for more details.

\section{E. Boundary Layer Transition}

Although at the present time an all-turbulent heating profile is being used for the design of the heat shield, the effect of boundary layer transition is still an important issue to understand from the perspective of being able to accurately determine the thermal margins that the designed TPS will have. For example, the actual time of laminarto-turbulent boundary layer transition for a lunar return is expected to be influenced by ablation (or blowing), laminar-ablated surface roughness, and flow chemistry. In contrast to a lunar return, significant ablation of the heat shield TPS is not expected during a lower velocity return from the ISS. In this scenario, boundary layer transition to turbulent flow is likely to be induced by distributed and/or isolated roughness associated with heat shield steps/gap tolerances or singularities in the TPS outer mold line (OML). There are very few experimental studies that characterize the effect of isolated roughness on blunt bodies in a supersonic or hypersonic flow. ${ }^{\text {xlv-xlix }}$ The publicly available information on blunt body flight transition data is summarized in Ref. xlv. A majority of this flight data involves ablating nose tips. ${ }^{1, \mathrm{li}, \mathrm{lii}}$ More appropriate to a capsule design, a few Apollo era reports exists on protuberances and/or cavities (Refs $\mathrm{x}$ and liii) but the focus is often on local heating. On the Orion TPS, surface 
roughness could exist in several forms: (1) distributed roughness associated with laminar and turbulent heat shield ablation, (2) localized non uniformities produced by gap fillers or manufacturing tolerances associated with the individual seams, if any, or (3) isolated roughness associated with hardware used to attach the CM to SM. Isolated step protuberances on Orion could arise from the tile-to-tile interfaces, as conceptually shown in Fig. 2 for a PICA design, in a manner similar to the Space Shuttle Orbiter. Another source of roughness at the tile interfaces are gap fillers. Gap fillers serve as a thermal barrier in areas where localized heating into gaps between adjacent tiles are unacceptable and to provide cushioning between tiles. Loose tile gap filler material between the tile interfaces can result in an isolated protuberance. Installation and bonding lessons learned

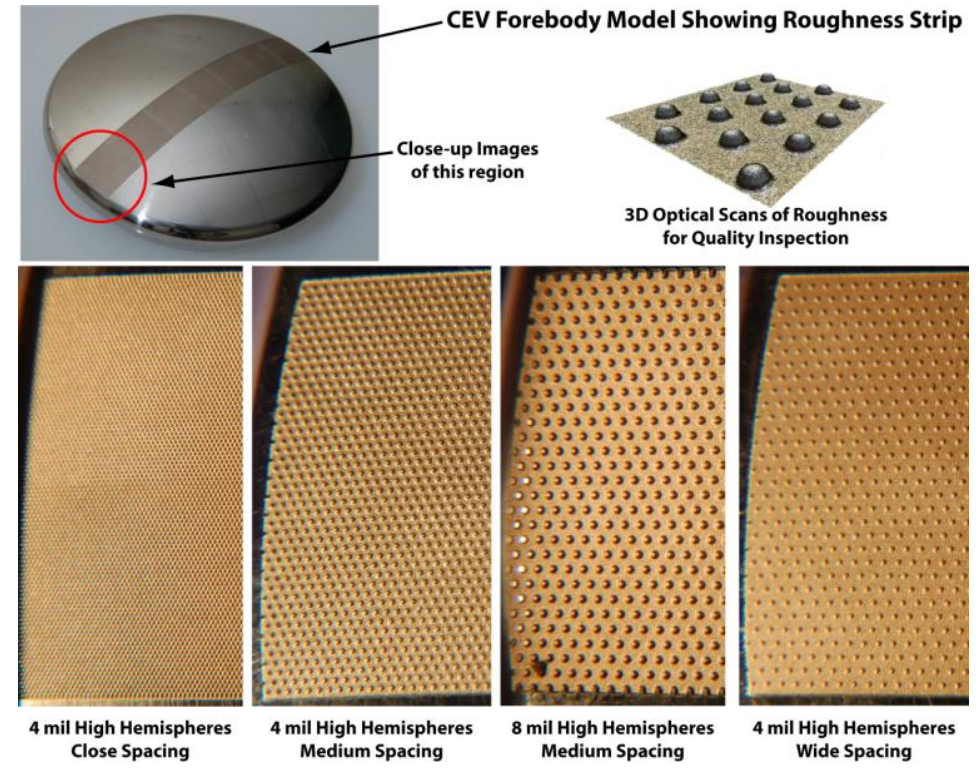

Figure 13. Sample distributed roughness patterns for 41-CH. from the Shuttle program will help mitigate this local type of surface non-uniformity. A preliminary study of boundary layer transition on the heat shield due to isolated protuberances was performed with the same model used earlier with 56-CH. These results were reported in Ref. liv. Also, separate studies were conducted with placing isolated protuberances on the aftbody using existing models but these results have not yet been published.

\section{F. Roughness \& Ablation}

As mentioned previously, there has been a concern with understanding the turbulent heating augmentation due to the presence of a distributed surface roughness. High lunar return velocities are likely to result in a surface roughness that differs significantly from the original heat shield condition due to ablation during entry. This is true whether the primary TPS material, Avcoat, is used or the back-up, PICA, although the scale of the roughness may be different between these two concepts. Thus, experimentally derived augmentations to the smooth-wall turbulent heating calculations for a range of roughness scales are required. A series of tests, listed in Table 5, have been undertaken to investigate the effect of surface roughness and mass transfer on turbulent heating. Test 41-CH provided the initial experimental results from a 3.5\% scale model in AEDC T9 with thin-skin gages for a series of distributed roughness heights and spacing. Figure 13 provides a sampling of a few of the distributed roughness models employed during this test. ${ }^{\text {Iv }}$ Recently, test $39-\mathrm{CH}$ was completed in LENS I with two different scale models, $12.12 \%$ and $24.24 \%$, with a similar series of distributed roughness patterns, including sandgrain roughness. Both of the 39-CH models utilized calorimeters at the surface. The results from both of these test entries are still being analyzed and will be documented in the near future. These first two studies focused on the potential turbulent heating augmentation due to distributed roughness without the surface blowing that is meant to simulate out gassing of the ablation products. There is a follow-up test planned for the LENS facility $(69-\mathrm{CH})$ in which the additional effect of surface blowing will be considered. The models for this test are presently in construction. Also captured in the test plan is one final opportunity for looking at roughness and blowing in a more systematic fashion in the LaRC Mach 6 tunnel $(90-\mathrm{CH})$, in case a second source for roughness and blowing data are needed to address any open issues.

Table 5: Roughness and ablation studies in support of CAP

\begin{tabular}{|c|c|c|c|c|c|}
\hline $\begin{array}{c}\text { Test } \\
\text { Number }\end{array}$ & \multicolumn{2}{|c|}{ Facility } & $\begin{array}{c}\text { Principal } \\
\text { Investigator }\end{array}$ & Conducted & Emphasis of the test \\
\hline $39-$ CH & CUBRC & LENS & Wilder & Aug-08 & Roughness only \\
\hline $41-C H$ & AEDC & T9 & Liechty & May-08 & Roughness only, 2 ${ }^{\text {nd }}$ source \\
\hline $69-$ CH & CUBRC & LENS & Wilder & Q4-FY09 & Roughness and blowing \\
\hline $90-$ CH & LaRC & M6 & Everhart & Q3-FY10 & Roughness \& blowing, 2 ${ }^{\text {nd }}$ source \\
\hline
\end{tabular}




\section{G. RCS Interactions}

Lastly, an experimental effort has been on going to investigate the local flow features and environments associated with the interactions of the Reaction Control System (RCS) thruster jets with the freestream flow. A series of tests in ground-based facilities have been conducted to help understand both the off-body fluid dynamics, as well as the surface heating, see Table 6. As shown in Fig. 6, a post-flight photograph of one of the RCS jets from Apollo 6, the heating footprint due to the jet interactions on the TPS was significant enough to char the surface. The intent of the experimental effort for RCS interactions is to provide for the current Orion design the key flow structures and surface heating that can be compared against the computational predictions. The initial RCS test, 37$\mathrm{CH}$, focused on demonstrating and improving measurement techniques for visualizing the complex threedimensional interactions both on and off the surface for comparison against predictions. Both temperature and pressure sensitive paints, for global heating and pressure measurements, and a scanning planar laser induced fluorescence (PLIF) technique for measuring plume shapes were used. These results have been published in Refs. lvi, lvii, lviii, and lix. A follow-on test, $63-\mathrm{CH}$, focused on providing quantitative heating data for comparison against prediction for combinations of single and dual jet firing configurations. These results are still being analyzed. Although not captured in the table below, 66-CH will also provide some significant RCS data for comparison against predictions. One final test, $95-\mathrm{CH}$, is being planned to capture any last minute changes to the final RCS design for Orion.

Table 6: RCS interaction studies in support of CAP

\begin{tabular}{|c|c|c|c|c|c|}
\hline $\begin{array}{c}\text { Test } \\
\text { Number }\end{array}$ & \multicolumn{2}{|c|}{ Facility } & $\begin{array}{c}\text { Principal } \\
\text { Investigator }\end{array}$ & Conducted & Emphasis of the test \\
\hline 37-CH & LaRC & M10 & Buck \& Danehy & Apr-May 07 & Test technique development \\
\hline 63-CH & LaRC & M10 & Buck \& Danehy & Jul-08 & Quantitative heating \\
\hline 95-CH & LaRC & M10 & Buck & Q2-2010 & High fidelity data \\
\hline
\end{tabular}

As an example, 37-CH investigated the effects of RCS jet interactions on the aft-body of a capsule entry vehicle in the LaRC Mach 10 tunnel and the final test report is provided in Ref. lx. The test focused on demonstrating and improving advanced measurement techniques that would aid in the rapid measurement and visualization of jet interaction effects for the Orion Crew Exploration Vehicle while providing data that would be useful for developing engineering models or validation of computational tools used to assess actual flight environments. Test measurements included global surface pressure and heat-transfer imaging with complementary three-dimensional flow visualization. The wind tunnel model was fabricated with interchangeable parts for two different aft-body configurations. The first, an Apollo-like configuration, was used to focus primarily on the forward facing roll and yaw jet interactions which are known to have significant aft-body heating augmentation with factors of 11 and 4 respectively. The second, an early Orion Crew Module configuration (4-cluster jets) was tested, blowing only out of the most windward yaw jet, which was expected to have the maximum heating augmentation. A rapid prototyping plastic/ceramic composite material was used directly for aero-heating substrates and was coated with a temperaturesensitive paint for global surface heating measurements. Interchangeable parts were also manufactured for pressuresensitive paint measurements on the aft-body, but were first coated with copper $(0.025$ " thick) to dissipate heat and provide a uniform temperature surface. Nitric oxide planar laser induced fluorescence was used for flow visualization. The test model was 5 inches in diameter and angle of attack set at 156-deg. Jet nozzles had a 0.0275-

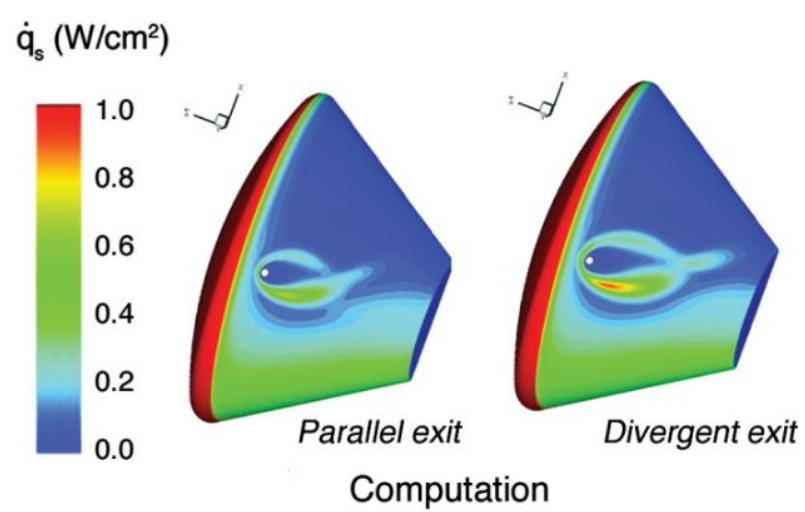

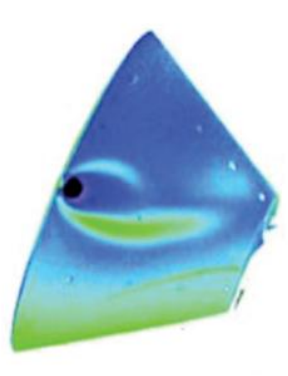

Experiment

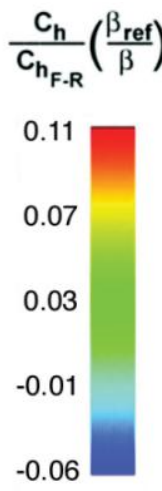

Figure 14. Comparison of measured yaw jet surface interactions from 37-CH to predictions. 
inch diameter throat and an exit area to throat ratio of 22.5. Jet chamber pressures were set at 250 and 500 psi and tunnel flow conditions run at free-stream Reynolds numbers based on model diameter of $0.23 \times 10^{6}$ and $0.75 \times 10^{6}$. Heating augmentation results were similar to the results of Jones and Hunt (1965) for the Apollo-like configuration and heating augmentation from the Orion windward yaw jet was at a similar level as that

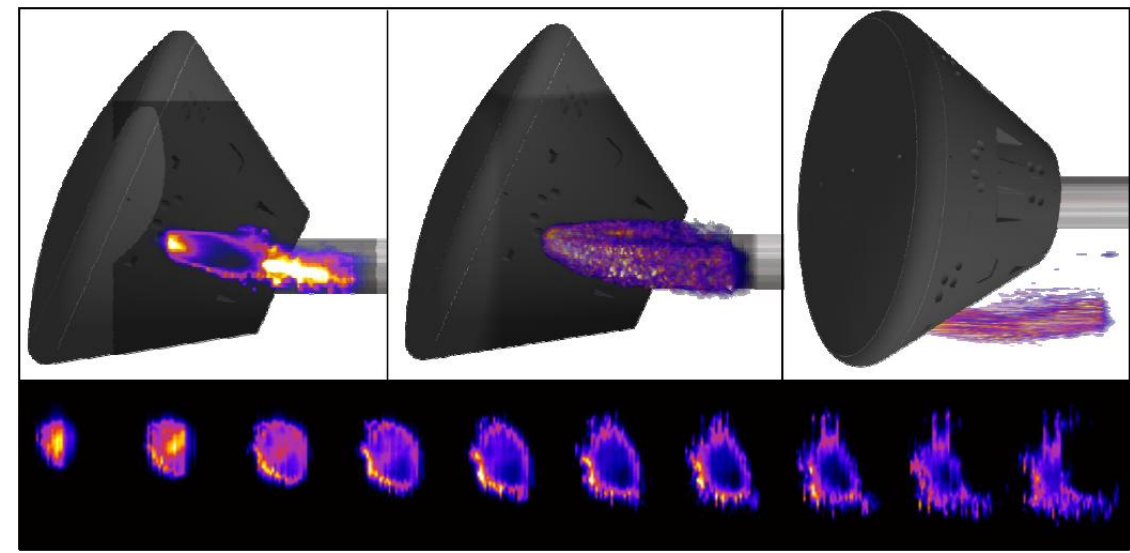

Figure 15. PLIF measurements of yaw jet plume from 37-CH. for the Apollo, but affected much less area. Figure 14 provides, for a yaw jet, a comparison to computational predictions of the aftbody surface heat transfer as inferred from the measured temperature data (from Ref. lvi). Figure 15 provides the corresponding PLIF image of the plume shape resulting from a single yaw jet firing, taken from Ref. lix. Comparisons of these experimental plume shapes to computations have yet to be completed. 63-CH investigated jet interaction heating for a later CM design configuration and heating data were calibrated and reduced to quantitative values and mapped to three-dimensional surface coordinates. The test report for $63-\mathrm{CH}$ is provided in Ref. lxi.

\section{Conclusion}

An overview of the Project Orion CEV aerothermal ground testing strategy is provided. The role of the experimental data, as both validation of the computational methods that are being used to develop the smooth body database for flight and the technical basis for the generation of engineering methodologies for dealing with deviations from the smooth OML, is discussed. Working groups have been formed around the key issues that are likely to require focused analysis or the use of an engineering method. The facilities that have supported CAP aerothermal testing are reviewed, along with some of the important results obtained thus far. Comparison of smooth wall computational predictions against experimental data from several facilities provided confidence with the use of algebraic turbulence model solutions as part of the database. Experimental data on cavities and protuberances are being used to parametrically screen the design space, plus support engineering method development as necessary. With the RCS testing, experimental data was acquired on the surface in combination with off-body flow visualization of the jet plumes and interactions. These results are being compared against predictions for improved understanding of aftbody uncertainties.

\section{References}

i "NASA's Exploration Systems Architecture Study, Final Report,” NASA TM-2005-214062, November, 2005.

${ }^{\text {ii }}$ Greathouse, J. S., Kirk, B. S., Lillard, R. P., Truong, T. H., Robinson, P., Cerimele, C. J., "Crew Exploration Vehicle (CEV) Crew Module shape selection analysis and CEV Aeroscience Project Overview," AIAA Paper 2007-603, 45th AIAA Aerospace Sciences Meeting and Exhibit, Reno, NV, Jan. 8-11, 2007.

iii Kinney, D. J., "Development of the ORION Crew Exploration Vehicle's Aerothermal Database Using A Combination of High Fidelity CFD and Engineering Level Methods,” AIAA Paper 2009-1100, Jan. 2009.

${ }^{i v}$ Wright, M. J., Prabhu, D. K., Martinez, E. R., "Analysis of Apollo Command Module Afterbody Heating Part I: AS-202," Journal of Thermophysics and Heat Transfer, Vol. 20, No. 1, 2006, pp. 16-30.

${ }^{v}$ Wray, A. A., Ripoll, J. F., and Prabhu, D. K., "Computations of Radiation in the Apollo AS-501 Reentry Using Opacity Distribution Functions," AIAA Journal, Vol. 45, No. 9, pp. 2359-2363, Sep. 2007.

${ }^{\text {vi }}$ Dirling, R. B., “A Method for Computing Roughwall Heat Transfer Rates on Reentry Nosetips,” AIAA Paper 73-763, Jul. 1973.

vii Finson, M.L., Wu, P.K.S. "Analysis of Rough Wall Turbulent Heating with Application to Blunted Flight Vehicles." AIAA 1979-0008, 17th Aerospace Sciences Meeting. New Orleans, LA, Jan. 1979.

viii Nestler, D.E. “Compressible Turbulent Boundary Layer Heat Transfer to Rough Surfaces.” AIAA 1970-742, 3rd Fluid and Plasma Dynamics Conference. Los Angeles, CA. June 1970. 
${ }^{i x}$ Voisinet, R. L. P., "Combined Influence of Roughness and Mass Transfer on Turbulent Skin Friction at Mach 2.9," AIAA Paper 79-0003, Jan. 1979.

${ }^{x}$ Bertin, J. J., "The Effect of Protuberances, Cavities, and Angle-of-attack on the Wind-Tunnel Pressure and Heat-Transfer Distribution for the Apollo Command Module," Technical Memorandum NASA-TM-X-1243, NASA, October 1966.

${ }^{x i}$ Liechty, D.S., "Aerothermodynamic Testing of Protuberances and Penetrations on the NASA Crew Exploration Vehicle Heat Shield," AIAA Paper 2008-1240, 46th AIAA Aerospace Sciences Meeting and Exhibit, Reno, NV, Jan. 7-10, 2008.

xii Miller, C. G., "Langley Hypersonic Aerodynamic/Aerothermodynamic Testing Capabilities - Present and Future," AIAA Paper 90-1376, 1990.

xiii Micol, J. R., "Langley Aerothermodynamic Facilities Complex: Enhancements and Testing Capabilities," AIAA Paper 980147, 1998.

${ }^{\text {xiv }}$ Hornung, H.G., Sturtevant, B., Belanger, J., Sanderson, S.R., Brouillette, M., and Jenkins, M., "Performance Data of the New Free-Piston Shock Tunnel T5 and GALCIT," Proceedings of the 18th International Symposium on Shock Waves, Jul. 1995.

${ }^{x v}$ Sanderson, S. R. "Shock Wave Ineraction in Hypervelocity Flow," PhD thesis, California Institute of Technology, Pasadena, CA, May 1995.

xvi Coblish, J. J., and Davenport, A. H., "Recent Efforts at AEDC's Von Karman Facility and Hypervelocity Wind Tunnel 9 to Enhance Facility Compatibility”, AIAA Paper 2002-2787, 22nd AIAA Aerodynamic Measurement Technology and Ground Testing Conference, June 24-26, 2002.

xvii Ragsdale, W. C., and Boyd, C. F., "Hypervelocity Wind Tunnel 9 Facility Handbook, Third Edition," Technical Report NAVSWC TR 91-616, Naval Surface Warfare Center, Silver Spring, MD, July 1993.

xviii Marren, D., and Lafferty, J., "The AEDC Hypervelocity Wind Tunnel 9," Advanced Hypersonic Test Facilities, Progress in Aeronautics and Astronautics, Vol. 198, American Institute of Aeronautics and Astronautics, Reston, VA, 2002, pp. $467-477$. "NASA's Exploration Systems Architecture Study, Final Report,” NASA TM-2005-214062, November, 2005.

${ }^{\text {xix }}$ Norris, J. D., Lafferty, J. F., Smith, M. S., Collier, A. S., and Hand, T., "Design and Aerodynamic Calibration of the New AEDC Hypervelocity Wind Tunnel No. 9 Mach 8 Nozzle," AIAA Paper 2005-4278, 41st AIAA/ASME/SAE/ASEE Joint Propulsions Conference and Exhibit, Tuscon, AZ, June 10-13, 2005.

${ }^{x x}$ CUBRC Research Staff, "Large Energy National Shock Tunnel (LENS) Description and Capabilities Rev.3", CUBRC, Buffalo, NY, April 2009.

${ }^{x x i}$ Sharma, S. P., and Park, C., "Operating Characteristics of a 60- and 10-cm Electric Arc-Driven Shock Tube, Part 1: The Driver," Journal of Thermophysics and Heat Transfer, Vol. 4, No. 3, 1990, pp. 259-265.

xxii' Sharma, S. P., and Park, C., "Operating Characteristics of a 60- and 10-cm Electric Arc-Driven Shock Tube, Part 2: The Driven Section,” Journal of Thermophysics and Heat Transfer, Vol. 4, No. 3, 1990, pp. 266-272.

xxiii Sharma, S. P., "NASA Ame's Electric Arc-Driven Shock Tube Facility and Research on Nonequilibrium Phenomena in Low Density Hypersonic Flows,” AIAA Paper 92-3975, July 1992.

${ }^{\text {xxiv }}$ Berger, K. T., "Aerothermodynamic Testing of the Crew Exploration Vehicle in the LaRC 20-Inch Mach 6 and 31-Inch Mach 10 Tunnels,” AIAA Paper 2008-1225, Jan. 2008.

${ }^{\mathrm{xxv}}$ Hollis, B. R., Horvath, T. J., Berger, K. T., Lillard, R. P., Kirk, B. S., Coblish, J. J., and Norris, J. D., "Experimental Investigation of Project Orion Crew Exploration Vehicle Aeroheating in AEDC Tunnel 9," NASA/TP-2008-215547, Dec. 2008.

${ }^{\text {xxvi }}$ Kurits, I., Lewis, M.J., Hamner, M. P., Global Heat-Transfer Measurements on the NASA Crew Exploration Vehicle at AEDC Tunnel 9," AIAA Paper 2008-3947, June 2008.

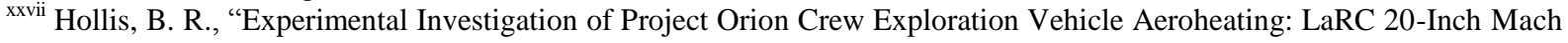
6 Air Tunnel Test 6931,” NASA TM 2009-215718, Apr. 2009.

xxviii Hollis, B. R., Berger, K. T., Horvath, T. J., Coblish, J. J., Norris, J. D., Lillard, R. P., Kirk, B. S., “Aeroheating Testing and Predictions for Project Orion CEV at Turbulent Conditions," AIAA Paper 2008-1226, Jan. 2008.

xxix Wadhams, T. P., Cassady, A. M., MacLean, M., and Holden, M. S., "Experimental Studies of the Aerothermal Characteristics of the Project Orion CEV Heat Shield in High Speed Transitional and Turbulent Flows," AIAA Paper 2009-667, Jan. 2009.

${ }^{\mathrm{xxx}}$ Menter, F. R., “Two-Equation Eddy-Viscosity Turbulence Models for Engineering Applications,” AIAA Journal, Vol. 32, No. 8, pp.1598-1605, Aug. 1994.

${ }^{x x x i}$ Cebeci, T., Bradshaw, P., “Momentum Transfer In Boundary Layers,” Hemisphere Publishing Corporation, Washington, D.C., 1977.

xxxii Baldwin, B. S., and Lomax, H., "Thin Layer Approximation and Algebraic Model for Separated Turbulent Flows," AIAA 1978-257, 16th AIAA Aerospace Sciences Meeting, Jan. 1978.

xxxiii Berger, K. T. and Nowak, R. J., "Aerothermodynamic Testing of the Cycle I Crew Exploration Vehicle Crew Module in the LaRC 20-Inch Mach 6 and 31-Inch Mach 10 Tunnels," EG-CAP-06-156, Nov. 2006.

${ }^{\text {xxxiv }}$ Grinstead, J. H., Wilder, M. C., Olejniczak, J., Bogdanoff, D. W., Allen, G. A., Dang, K., and Forrest, M. J., "Shockheated Air Radiation Measurements at Lunar Return Conditions," AIAA Paper 2008-1244, Jan 2008.

xxxv Johnston, C. O., "A Comparison of EAST Shock-Tube Radiation Measurements with a New Air Radiation Model," AIAA Paper 2008-1245, Jan 2008.

xxxvi Bose, D., McCorkle, E., Thompson, C., Bogdanoff, D. W., Prabhu, D., Allen, G. A., Grinstead, J. H., "Analysis and Model Validation of Shock Layer Radiation in Air," Paper 2008-1246, Jan 2008. 
xxxvii Thompson, C., Fletcher, D., and Bose, D., "Analysis of Spectrally Resolved Shock-Layer Emission for Lunar Return Trajectory Conditions", AIAA Paper 2008-3813, Jun. 2008.

xxxviii Johnston, C. O., Gnoffo, P. A., and Sutton, K., "The Influence of Ablation on Radiative Heating for Earth Entry," AIAA Paper 2008-4107, June 2008.

xxxix Kleb, B.,and Johnston, C. O., "Uncertainty Analysis of Air Radiation for Lunar Return Shock Layers," AIAA Paper 2008-6388, Aug. 2008.

xl Bose, D., McCorkle, E., Bogdanoff, D., and Allen, G., "Comparison of Air Radiation Model with Shock Tube Measurements", AIAA Paper 2009-1030, Jan. 2009.

xli McCorkle, E., Bose, D., Hash, D., and Hassan, H., "Improved Modeling of Shock Layer Radiation in Air", AIAA Paper 2009-1028, Jan. 2009.

xlii Liechty, D. S., "Aerothermodynamic Testing of Protuberances and Penetrations on the NASA Cycle I Crew Exploration Vehicle Heat Shield in the NASA Langley 20-Inch Mach 6 Air Tunnel: Test 6918," EG-CAP-06-155, Nov. 2006.

xliii Hollis, B. R., "Heating Augmentation in Laminar Flow Due to Heat-Shield Cavities on the Project Orion CEV," AIAA Paper 2008-6558, Aug. 2008.

${ }^{\text {xliv }}$ Hollis, B. R., Lessard, V., Jentink, T., "Heating Augmentation Due to Compression Pad Cavities on the Project Orion CEV Heat Shield," AIAA Paper 2009-3843, June 2009.

${ }^{x l v}$ Schneider, S. P., "Hypersonic Boundary-Layer Transition on Blunt Bodies with Roughness," AIAA Paper 2008-0501, 46 ${ }^{\text {th }}$ AIAA Aerospace Sciences Meeting and Exhibit, Reno, NV, Jan. 7-10, 2008.

${ }^{x l v i}$ Schneider, S. P., "Laminar-Turbulent Transition on Reentry Capsules and Planetary Probes," J. of Spacecraft and Rockets, Vol. 43, No. 6, pp. 1153-1173, Nov.-Dec. 2006. See erratum with correct color figures, Vol. 44, No. 2, pp. 464-484, March-April 2007.

xlvii Schneider, S. P., "Effects of Roughness on Hypersonic Boundary-Layer Transition," AIAA Paper 2007-0305, 45th AIAA Aerospace Sciences Meeting and Exhibit, Reno, NV, January 2007. Revised version to appear in the J. of Spacecraft and Rockets.

${ }^{x l v i i i}$ Reda, D. C., "Correlation of Nosetip Boundary-Layer Transition Data Measured in Ballistics-Range Experiments," AIAA Journal, Vol. 19, No. 3, pp. 329-339, March 1981.

xlix Batt R. G., and Legner, H.H., “A Review of Roughness-Induced Nosetip Transition,” AIAA Journal, Vol. 21, No. 1, pp. 7-22, January 1983.

${ }^{1}$ Kaattari, G. E., "Effects of Mass Addition on Blunt-Body Boundary-Layer Transition and Heat Transfer." Technical Report NASA-TP-1139, NASA, January 1978.

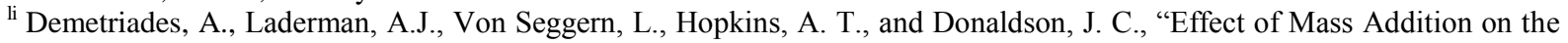
Boundary Layer of a Hemisphere at Mach 6," J. of Spacecraft and Rockets, Vol.13, No. 8, p. 508, August 1976.

lii Laganelli, A.L. and Martelluci, A., "Downstream Effects of Gaseous Injection through a Porous Nose. AIAA Paper $72-$ $185,1972$.

liii Emerson, R.X., "Experimental Heat Transfer Distributions over the 0.090-scale Apollo Command Module (H-11) with Protuberances at Mach Number 10. Contractor Report NASA-CR- 117540, NASA, November 1964. NASA STI citation 79 N76583.

liv Amar, A. J., Horvath, T. J., Hollis, B. R., Berger, K. T., Berry, S. A., and Calvert, N., "Protuberance Boundary Layer Transition for Project Orion Crew Entry Vehicle,” AIAA Paper 2008-1227, Jan. 2008.

${ }^{\text {lv }}$ Lewis, D. R. and Norris, J. D., "Techniques for Thin-Skin Heat-Transfer Measurements for Surface Roughness at AEDC Tunnel 9," AIAA Paper 2008-3950, June 2008.

lvi Buck, G. M., Watkins, A, N., Danehy, P. M., Inman, J. A., Alderfer, D. W., and Dyakonov, A. A., "Experimental Measurement of RCS Jet Interaction Effects on a Capsule Entry Vehicle," AIAA Paper 2008-1229, Jan. 2008.

lvii Watkins, A, N., Buck, G. M., Leighty, B. D., Lipford, W. E., and Oglesby, D. M., "Using Pressure- and TemperatureSensitive Paint for Global Surface Pressure and Temperature Measurements on the Aft-Body of a Capsule Reentry Vehicle," AIAA 2008-1230, Jan. 2008.

lviii Danehy, P. M., Inman, J. A., Alderfer, D. W., Buck, G. M., and Bathel, B., "Visualization of Flowfield Modification by RCS Jets on a Capsule Entry Vehicle,” AIAA 2008-1231, Jan. 2008.

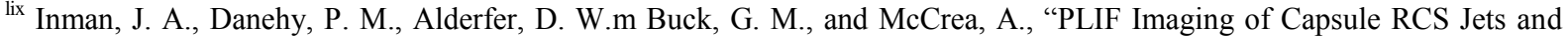
Simulated Forebody Ablation,” AIAA Paper 2008-248, Jan. 2008.

${ }^{1 x}$ Buck, G. M., "Aerothermodynamic Testing of RCS Jet Interactions on Apollo and Orion-type Crew Modules in the NASA Langley 31-Inch Mach 10 Air Tunnel: Test 37-CH,” EG-CAP-07-97, Aug. 2007.

lxi Buck, G. M., "Aerothermodynamic Testing of RCS Jet Interactions for the Orion 606D Crew Module in the NASA Langley 31-Inch Mach 10 Air Tunnel: Test 63-CH,” EG-CAP-08-173, April 2009. 